\title{
PENGARUH PENGGUNAAN TEMPURUNG KELAPA SEBAGAI PENAMBAH AGREGAT KASAR MUTU BETON F'C 17 Mpa TERHADAP KUAT TEKAN BETON
}

\author{
Syafiatun Siregar ${ }^{1}$, Nurmaidah ${ }^{2}$ \\ ${ }^{1}$ Dosen Pengajar Jurusan Pendidikan Teknik Bangunan, Fakultas Teknik UNIMED \\ ${ }^{2}$ Dosen Program Studi Sipil Fakultas Teknik, Universitas Medan Area \\ (syafiatunsiregar@gmail.com, nurmaidahmidah@gmail.com)
}

\begin{abstract}
ABSTRAK
Pada pembangunan beton banyak di gunakan umumnya bangunan sipil. Bahan dasar dari beton ialah campuran semen, air, agregat halus dan agregat kasar, sedangakan beton yang menggunakan tulangan baja disebut beton bertulang. Sesuai perkembangan zaman dengan teknologi yang mendukung mengakibatkan terus bertambahnya jumlah barang bekas dan berbagai macam limbah yang keberadaannya menjadi masalah bagi kehidupan, salah satunya adalah limbah tempurung kelapa. Tempurung kelapa ini dapat diperoleh di berbagai tempat dan dapat diolah pada industri pabrik seperti obat nyamuk, arang menjadi karbon aktif, pinsil dan lain sebagainya.

Penelitian ini tempurung kelapa digunakan sebagai bahan tambahan pada campuran beton normal. Variasi penambahan tempurung kelapa pada beton normal untuk mengetahui kuat tekan beton yang diharapkan dapat meningkatkan kualitas beton berupa kuat tekan. Adapun variasi tempurung kelapa yang digunakan adalah $0 \%, 10 \%, 20 \%$, dan 30\%.Sehingga hasil kuat tekan beton yang di peroleh dari variasi tersebut adalah 54,72 ton , 28,75 ton , 28,59 ton dan 22,969 ton.
\end{abstract}

Kata Kunci : beton, kuat tekan, slump, tempurung kelapa

\begin{abstract}
On the construction of concrete used in general civil buildings. The basic ingrendient of concrete is a mixture of cement, water, fine aggregate and coarse aggregate, while the concrete using steel reinforcement called reinforced concrete. According to the times with technology that supports resulted in increasing number of second - hand goods and a wide variety of waste whose existence is aproblem for life, one of which waste coconut shell. Coconut shell can be obtained in a variety of place and can be processed in industrial plants such as insect repellent, be carbon activated charcoal, pencil and so forth.

This study coconut shell is used as an additive in a mixture of normal concrete. The addition of coconut shell variation on normal concrete to determine the compressive strenght of concrete is expected to improve the quality of the compressive strenght of the concrete form. As for the variation of coconut shells used were $0 \%, 10 \%, 20 \%$ and $30 \%$. So rthat the compressive stregth of concrete obtained from the variation is 55.72 tons, 28.75 tons, 28.59 tons and 22.969 tons.
\end{abstract}

Keywords: Integrative Learning Model, Learning Outcomes, foundations Survey and Mapping 


\section{Pendahuluan}

Industri - industri di indonesia yang sangat pesat, sebagian besar material yang digunakan dalam pekerjaan konstruksi adalah beton (concrete) yang berpadu dengan baja (composite) atau berbagai jenis lainnya.

Beton merupakan campuran antara semen, agregat halus, agregat kasar dan air. Bahan bahan yang digunakan biasanya digunakan dalam campuran beton pada saat atau berapa lama waktu pencampuran berlangsung, berfungsi untuk mengubah sifat - sifat dari beton agar menjadi lebih cocok dalam pekerjaan tertentu dan lebih ekonomis.

Limbah adalah bahan - bahan yang tidak bisa di pakai lagi sebagai fungsi yang sama. Akan tetapi sebagian besar limbah dapat di daur ulang dengan manfaat yang berbeda dan berkualitas baik. Disamping itu banyak bermacam jenis pohon yang hidup di daerah tersebut seperti pohon kelapa atau disebut juga dengan pohon nyiur.

Berawal dari akar sebagai bahan obat obatan, daun sebagai alat pembersih (sapu), batang sebagai bahan konstruksi, serta hingga buahnya sebagai santan atau sebagainya. Tempurung kelapa memiliki beberapa kandungan seperti lignin, pentosan, selulosa, air, solvent ekstraktif, uronat anhidrat, abu, dan nitrogen. Sehingga tempurung kelapa dapat atau tidaknya meningkatkan karakteristik beton.

\section{Landasan Teori}

Beton merupakan fungsi dari bahan penyusunannya yang terdiri dari bahan semen hidrolik (portland cement), agregat kasar, agregat halus, air dan bahan tambah (admixture atau additive).

Untuk mengetahui dan mempelajari perilaku elemen gabungan (bahan-bahan penyusun beton), kita memerlukan pengetahuan mengenai karakteristik masing - masing komponen. Nawy (1985:8) beton sebagai sekumpulan interaksi mekanis dan kimiawi material pembentuknya.

Dengan demikian, masing - masing komponen tersebut perlu dipelajari sebelum memepelajari beton secara keseluruhan. Beton juga tahan terhadap serangan korosi. Secara umum kelebihan dan kekurangan beton adalah:

\section{Kelebihan}

a. Dapat dengan mudah dibentuk sesuai dengan kebutuhan konstruksi

b. Mampu memilkul beban yang berat

c. Tahan terhadap temperatur yang tinggi

d. Biaya pemiliharaan yang kecil

\section{Kekurangan}

a. Bentuk yang telah dibuat sulit diubah

b. Pelaksanaan pekerjaan membutuhkan ketelitian yang tinggi

c. Berat

d. Daya pantul suara yang besar

\subsection{Semen Portland}

Semen portland adalah bahan konstruksi yang paling banyak digunakan dalam pekerjaan beton. Menurut ASTM C - 150,1985, semen portland didefinisikan sebagai semen hidrolik yang dihasilkan dengan menggiling klinker yang terdiri dari kalsium silikat hidrolik, yang umumnya mengandung satu atau lebih bentuk kalsium sulfat sebagai bahan tambahan yang digiling bersama - sama dengan bahan utamanya.

\subsection{Agregat}

Kandungan agregat dalam campuran beton biasanya sangat tinggi. Berdasarkan pengalaman, komposisi agregat tersebut berkisar $60 \%-70 \%$ dari berat campuran beton. Walaupun fungsinya hanya sebagai pengisi, tetapi karena komposisinya yang cukup besar, agregat inipun menjadi penting. Karena itu perlu dipelajari karakteristik agregat yang akan menentukan sifat mortar atau beton yang akan dihasilkan.

Sifat yang paling penting dari suatu agregat (batu - batuan, kerikil, pasir dan lain lain) ialah kekuatan hancur dan ketahanan terhadap benturan, yang dapat mempengaruhi ikatannya dengan pasta semen, porositas dan karakteristik penyerapan air yang mempengaruhi daya tahan terhadap proses pembekuan waktu musim dingin dan agresi kimia, serta ketahanan terhadap penyusutan.

\subsection{Air}

Air yang dapat diminum umumnya dapat digunakan sebagai campuran beton. Air yang mengandung senyawa - senyawa yang 


\section{Pengaruh Penggunaan Tempurung Kelapa Sebagai Penambah Agregat Kasar Mutu Beton F'C 17 Mpa Terhadap Kuat Tekan Beton}

berbahaya, yang tercemar garam, minyak, gula, atau bahan kimia lainnya, bila dipakai dalam campuran beton akan menurunkan kualitas beton, bahkan dapat mengubah sifat - sifat beton yang dihasilkan. Air yang digunakan dapat berupa air tawar (dari sungai, danau, telaga, kolam, dan lainnya), air laut maupun air limbah, asalkan memenuhi syarat mutu yang telah ditetapkan. Air tawar yang dapat diminum umumnya dapat digunakan sebagai campuran beton. Air laut umumnya mengandung 3,5\% larutan garam $(78 \%$ sodium klorida dan 15\% magnesium klorida). Garam dalam air dapat mengurangi kualitas campuran beton hingga $20 \%$.

\subsection{Faktor Air Semen (FAS)}

Secara umum diketahui semakin tinggi nilai FAS, semakin rendah mutu beton Demikian nilai Fas yang semakin rendah tidak selalu berarti bahwa kekuatan beton semakin tinggi. Ada batas - batas dalam hal ini. Nilai FAS yang rendah akan menyulitkan dalam pengerjaan, yaitu kesulitan dalam pelaksanaan pemadatan yang pada akhirnya akan menyebabkan mutu beton menurun. Umumnya nilai FAS minimum yang diberikan sekitar 0,4 dan maksimum 0,65.

\subsection{Tempurung Kelapa (Material Tambahan)}

Pohon kelapa atau sering disebut pohon nyiur biasanya tumbuh pada daerah atau kawasan tepi pantai. Kelapa (Cocos nucifera) adalah anggota tunggal dalam marga Cocos dari suku aren - arenan atau Arecaceae. Kelapa secara alami tumbuh di pantai dan pohonnya mencapai ketinggian $30 \mathrm{~m}$. Ia berasal dari pesisir Samudera Hindia, namun kini telah tersebar di seluruh daerah tropika. Tumbuhan ini dapat tumbuh hingga ketinggian $1.000 \mathrm{~m}$ dari permukaan laut, namun seiring dengan meningkatnya ketinggian, ia akan mengalami pelambatan pertumbuhan.

Klasifikasi ilmiah tanaman kelapa ialah:
a. Kerajaan
: Plantae
b. Ordo
: Arecales
c. Famili
: Arecaceae
d. Upafamili
: Arecoideae
e. Bangsa
: Cocoeae
f. Genus
:Cocos
g. Spesies
: C. nucifera
h. Nama binomial
: Cocos nucifera

Buah kelapa terdiri dari kulit luar, sabut, tempurung, kulit daging (testa), daging buah, air kelapa dan lembaga. Buah kelapa yang sudah tua memiliki bobot sabut $(35 \%)$, tempurung $(12 \%)$, endosperm $(28 \%)$ dan air $(25 \%)$ (Setyamidjaja, D., 1995). Tempurung kelapa adalah salah satu bahan karbon aktif yang kualitasnya cukup baik dijadikan arang aktif.

Bagian tempurung kelapa merupakan bagian yang paling keras dibandingkan dengan bagian kelapa lainnya. Struktur yang keras disebabkan oleh silikat (SiO2) yang cukup tinggi kadarnya di tempurung tersebut. Berat dan tebal tempurung kelapa sangat ditentukan oleh jenis tanaman kelapa. Berat tempurung kelapa sekitar $15 \%-19 \%$ dari berat keseluruhan buah kelapa, sedangkan tebalnya sekitar $3 \mathrm{~mm}-5 \mathrm{~mm}$.

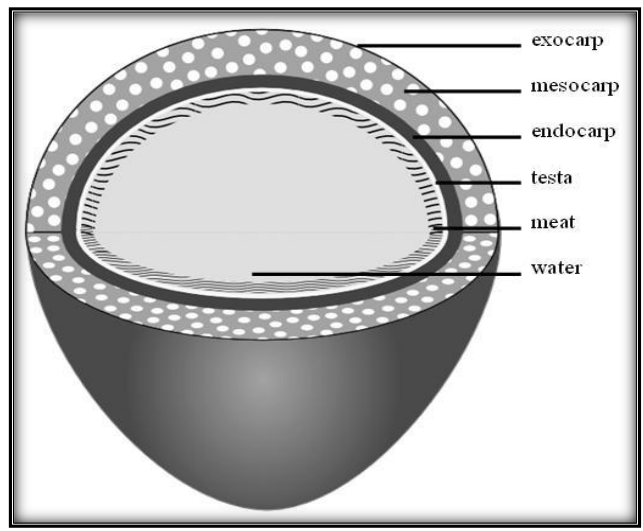

Gambar 1. Bagian Tempurung Kelapa

\section{Metodologi Penelitian}

Metode pengujian pada material beton yaitu agregat kasar dan agregat halus dilakukan sesuai pengujian, yaitu sebagai berikut:

a. Berat jenis dan penyerapan air sesuai dengan SK SNI M 09 - 1989 - F (agregat kasar dan agregat tambahan) dan SK SNI M 10 - 1989 - F (agregat halus).

b. Berat isi sesuai dengan ASTM C - 91a - 78

c. Analisa ayakan sesuai dengan SK SNI M 08 - 1989 - F

d. Kadar lumpur sesuai dengan ASTM C 117 95

e. Organik impuritis sesuai dengan ASTM C $40-92$

f. Kadar air sesuai dengan SK SNI M 11 - 1989 - F.

Setelah didapat sifat fisik agregat dan sifat fisik agregat tambahan dengan persyaratan yang sesuai dengan beton menurut 
SII No.0052 - 80. Persyaratan tersebut dapat dianalisa apakah agregat memenuhi syarat atau tidak . selanjutnya untuk mengetahui sifat fisik beton baik beton segar maupun beton keras maka dilakukan pengujian berdasarkan standar pengujian, sebagai berikut :

1. Pengujian terhadap beton segar

a. Uji slump sesuai dengan SK SNI M - 12 1989 - F

b. Berat isi sesuai dengan ASTM C 138 - 92

2. Pengujian terhadap beton keras

a. kuat tekan sesuai dengan SK SNI M - 14 - 1989 - F

b. kuat tarik belah sesuai dengan SK SNI M - $14-1989$ - F

\subsection{Bahan - bahan penelitian}

Penelitian ini bahan - bahan material yang digunakan adalah:

a. Semen yang digunakan semen portland type 1 dengan merk Semen Padang.

b. Air yang digunakan adalah air yang tersedia di Laboratorium Beton Teknik Sipil Universitas Medan Area.

c. Agregat halus yang digunakan dari toko material yang diambil dari daerah Deli Serdang.

d. Agregat kasar yang digunkan dari toko material dengan ukuran $\leq 30 \mathrm{~mm}$ yang diambil dari patumbak.

\subsection{Perencanaan Campuran Beton}

Pembuatan benda uji beton dilaksanakan setelah perhitungan rencana campuran selesai, persiapan alat dan bahan dalam kondisi baik. Pembuatan benda uji beton dilakukan dalam satu kali adukan. Pengujian dilakukan pada umur benda uji 3 hari.

Langkah-langkah pembuatan benda uji beton adalah sebagai berikut :

a. Hitung $f^{\prime} \mathrm{cr}=\mathrm{f}^{\prime} \mathrm{c}+\mathrm{m}$

b. Berdasarkan $\mathrm{f}^{\prime} \mathrm{cr}$ tentukan fas, dengan bantuan tabel 1 diambil yang terkecil.

c. Tentukan berat semen minimum.

d. Tentukan berat air minimum per3 beton $=$ $\mathrm{Wa}=$ fas $\mathrm{x}$ Ws

e. Tentukan proporsi gradasiagregat gabungan sehingga masuk dalam rentang gradasi sesuai grafik. Kemudian tentukan persen (\%) pasir dan (\%) kerikil.

f. Tentukan kebutuhan agregat per $\mathrm{m} 3$ beton.

g. Wag.camp $=\mathrm{W}$ beton - Wair $-\mathrm{Ws}$

h. Tentukan kebutuhan agregat halus dan kasar per $\mathrm{m} 3$ beton. i. $\quad$ Misal $P=40 \%$

j. $\mathrm{K}=60 \%$

k. $\mathrm{Wpsr}=\mathrm{P} /(\mathrm{P}+\mathrm{K}) \times$ Wagg camp

1. $\mathrm{Wkrkl}=\mathrm{K} /(\mathrm{P}+\mathrm{K}) \times$ Wagg camp

$\mathrm{m}$. Proporsi berat antara semen : air : pasir : kerikil adalah :

n. Ws: Wa : Wpsr : Wkrkl

o. Kebutuhan semen : air : pasir : kerikil untuk satu kali adukan adalah banyaknya kubus dikali rata-rata kebutuhan untuk satu kubus.

p. Kubus $=0,15 \times 0,15 \times 0,15=0,003375 \mathrm{~m} 3$ Sehingga :
1) Pasir $=0,003375 \times \mathrm{W}$ psr
2) Kerikil $=0,003375 \times \mathrm{W}$ krkl
3) Air $=0,003375 \times$ Wair
4) Semen $=0,003375 \times$ Wsemen

\section{Pembahasan dan Hasil Penelitian}

Mix desaign mutu beton $17 \mathrm{MPa}$ dengan Portland Cement Type 1:

a. Kuat tekan yang disyaratkan $\mathrm{fc}^{\prime} 17 \mathrm{MPa}$ atau $173,3 \mathrm{~kg} / \mathrm{cm}^{2}$

b. Deviasi Standar: faktor pengali untuk deviasi standar dilihat dari tabel faktor pengali.

Standar deviasi $=4,5 \mathrm{MPa}$

c. Nilai tambah(margin) $z=M=1,64 \times 4,5=7,3$ $\mathrm{MPa}$

d. Kuat Tekan yang di targetkan $=17+7,3=$ $24,3 \mathrm{MPa}=247,7 \mathrm{Kg} / \mathrm{cm}^{2}$

e. Jenis semen $=$ semen portland type 1

f. Jenis agregat kasar $=$ batu pecah

g. BJ SSD agregat kasar $=2,6$

h. Jenis agregat halus $=$ pasir alami

i. BJ SSD agregat halus $=2,4$

j. Jenis agregat tambahan = tempurung kelapa

k. BJ SSD agregat tambahan $=1,9$

1. Faktor air semen (Fas) $=0,5$

m. Faktor air semen maksimum $=0,6$

n. Besar butir agregat kasar maksimum = $30 \mathrm{~mm}-3 \mathrm{~cm}$

o. Nilai slump rencana $=60-180 \mathrm{~mm}$ atau 6 $-18 \mathrm{~cm}$

p. Kadar air bebas $=10$

q. Kadar air $=(2 / 3 \times 175)+(1 / 3 \times 205)+10$ $=195 \mathrm{Kg} / \mathrm{m}^{3}$

r. Berat semen $=195 / 0,5=390 \mathrm{Kg} / \mathrm{m}^{3}$

s. Gradasi agregat halus $=$ Zone 1

t. Persentase agregat halus $\quad=40 \%$

u. Persentase agregat Kasar $\quad=60 \%$

v. Persentase agregat tambahan $\quad=0 \%$ ; $10 \% ; 20 \% ; 30 \%$

w. Bj agregat gabungan 


\section{Pengaruh Penggunaan Tempurung Kelapa Sebagai Penambah Agregat Kasar Mutu Beton F'C 17 Mpa Terhadap Kuat Tekan Beton}

1) Berat jenis gabungan $(0 \%$ AgregatTambahan)

$=(40 \% \times 2,4)+(60 \% \times 2,6)$ $=2,52$

2) Berat jenis gabungan (10\% Agregat Tambahan)

$=(40 \% \times 2,4)+(54 \% \times 2,6)+(6 \% \times 1,9)$ $=2,48$

3) Berat jenis gabungan (20\% Agregat Tambahan)

$=(40 \% \times 2,4)+(48 \% \times 2,6)+(12 \% \times 1,9)$ $=2,45$

4) Berat jenis gabungan (30\% Agregat Tambahan)

$=(40 \% \times 2,4)+(42 \% \times 2,6)+(18 \% \times 1,9)$ $=2,40$

$x$. Berat isi beton

1) $0 \%$ Agregat tambahan tempurung = $2325 \mathrm{Kg} / \mathrm{m}^{3}$

2) $10 \%$ Agregat tambahan tempurung = $2280 \mathrm{Kg} / \mathrm{m}^{3}$

3) $20 \%$ Agregat tambahan tempurung = $2225 \mathrm{Kg} / \mathrm{m}^{3}$

4) $30 \%$ Agregat tambahan tempurung = $2200 \mathrm{Kg} / \mathrm{m}^{3}$

y. Berat agregat halus

1) Agregat halus ( tambahan 0\%) $=696$ $\mathrm{Kg} / \mathrm{m}^{3}$

2) Agregat halus ( tambahan 10\%) $=678$ $\mathrm{Kg} / \mathrm{m}^{3}$

3) Agregat halus ( tambahan 20\% ) $=656$ $\mathrm{Kg} / \mathrm{m}^{3}$

4) Agregat halus ( tambahan 30\%) $=646$ $\mathrm{Kg} / \mathrm{m}^{3}$

z. Berat agregat kasar

1) Agregat kasar $($ tambahan $0 \%)=1044$ $\mathrm{Kg} / \mathrm{m}^{3}$

2) Agregat kasar $(\operatorname{tambahan} 10 \%)=915,3$ $\mathrm{Kg} / \mathrm{m}^{3}$

3) Agregat kasar ( tambahan 20\% ) =787,2 $\mathrm{Kg} / \mathrm{m}^{3}$

4) Agregat kasar ( tambahan 30\%) $=678,3$ $\mathrm{Kg} / \mathrm{m}^{3}$

aa. Berat agregat tambahan

1) Agregat tambahan (tempurung $0 \%$ ) = $0 \mathrm{Kg} / \mathrm{m}^{3}$

2) Agregat tambahan (tempurung 10\%) = $101,7 \mathrm{Kg} / \mathrm{m}^{3}$

3) Agregat tambahan (tempurung 20\% ) = $197 \mathrm{Kg} / \mathrm{m}^{3}$

4) Agregat tambahan (tempurung 30\%) = $291 \mathrm{Kg} / \mathrm{m}^{3}$
Pengujian Nilai Slump

Tabel 1: Pengujian Nilai Slump

\begin{tabular}{cccc}
\hline No. & $\begin{array}{c}\text { Jumlah } \\
\text { Tempurung } \\
\text { Kelapa (\%) }\end{array}$ & FAS & $\begin{array}{c}\text { Slump } \\
\text { (cm) }\end{array}$ \\
\hline 1 & 0 & 0,5 & 12 \\
2 & 10 & 0,5 & 11 \\
3 & 20 & 0,5 & 10 \\
\cline { 3 - 4 } 4 & 30 & 0,5 & 8 \\
\hline & Rata - rata & $\mathbf{0 , 5}$ & $\mathbf{1 0 , 2 5}$ \\
\hline
\end{tabular}

\section{Tinggi Slump Pada Penambahan Tempurung Kelapa Sebagai} Agregat Kasar

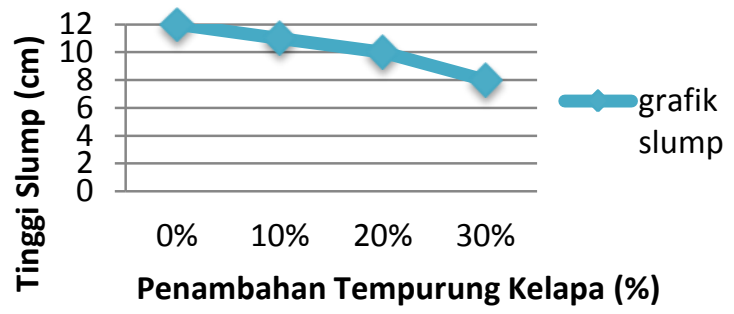

Gambar 2. Grafik Hubungan Tinggi Slump

Tabel 2: Hasil Pengujian Kuat Tekan Rata-rata

\begin{tabular}{cccc}
\hline $\begin{array}{c}\text { NO. } \\
\text { SAMPEL }\end{array}$ & FAS & $\begin{array}{c}\text { SLUMP } \\
\text { (CM) }\end{array}$ & $\begin{array}{c}\text { KUAT } \\
\text { TEKAN }\end{array}$ \\
\hline $0 \%$ & 0,5 & 12 & 243,83 \\
\hline $10 \%$ & 0,5 & 11 & 128,21 \\
\hline $20 \%$ & 0,5 & 10 & 127,50 \\
\hline $30 \%$ & 0,5 & 8 & 102,82 \\
\hline
\end{tabular}

Hasil Kuat Tekan Rata - Rata Tempurung Kelapa Sebagai Agregat Tambahan Terhadap Kerikil

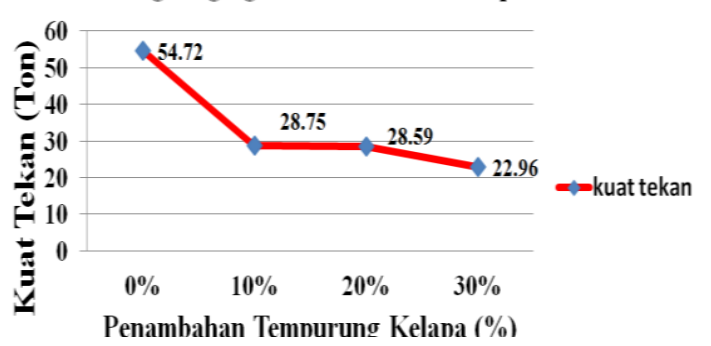

Gambar 3. Grafik Hasil kuat tekan rata-rata tempurung kelapa sebagai agregat tambahan terhadap kerikil 


\section{Kesimpulan dan Saran}

\subsection{Kesimpulan}

Dari penelitian yang dilakukan didapat hasil pengujian yang di awali dari pengujian agregat halus, pengujian agregat kasar, pengujian beton segar, hingga pengujian beton keras di laboratorium. Sehingga dapat ditarik kesimpulan penelitian sebagai berikut :

a. Penambahan tempurung kelapa pada campuran beton terhadap agregat kasar sebesar $0 \%, 10 \%, 20 \%$ dan 30\% menghasilkan nilai slump rata - rata yaitu :

a. Penambahan tempurung kelapa sebesar $0 \%$ nilai slump sebesar $12 \mathrm{~cm}$

b. Penambahan tempurung kelapa sebesar $10 \%$ nilai slump sebesar $11 \mathrm{~cm}$

c. Penambahan tempurung kelapa sebesar $20 \%$ nilai slump sebesar $10 \mathrm{~cm}$

d. Penambahan tempurung kelapa sebesar $30 \%$ nilai slump sebesar $8 \mathrm{~cm}$

b. Penambahan tempurung kelapa sebagai agregat kasar mempengaruhi massa jenis beton, dan kuat tekan beton yang diperoleh adalah :

a. Kuat tekan dengan $0 \%$ tempurung kelapa sebesar 243,83

b. Kuat tekan dengan 10\% tempurung kelapa sebesar 127,50

c. Kuat tekan dengan 20\% tempurung kelapa sebesar 128,21

d. Kuat tekan dengan 30\% tempurung kelapa sebesar 102,85

c. Campuran tempurung kelapa terhadap beton mempengaruhi kadar air saat pengadukan sehingga terjadinya penyerapan kadar air dalam beton segar dan menimbulkan aroma khas tempurung kelapa tersebut.

d. Dari hasil uji kuat tekan beton rata - rata dengan penambahan tempurung kelapa sebagai agregat kasar dari yaitu (TON) :

a. Dengan $0 \%$ tempurung kelapa sebesar 54,72

b. Dengan $10 \%$ tempurung kelapa sebesar 28,75

c. Dengan $20 \%$ tempurung kelapa sebesar 28,59

d. Dengan 30\% tempurung kelapa sebesar 22,969

\subsection{Saran}

Dari hasil penelitian dan beberapa pengujian di dapatkan kesimpulan sehingga dengan kesimpulan tersebut dapat diberikan saran saran sebagai berikut: a. Pada pengadukan beton hendaknya diperhatikan pencampuran agregat. Dimana tempurung kelapa harus dicampur dengan agregat kasar dan halus dan kemudian semen. Hal ini agar semua agregat mendapatkan kadar air yang optimal sehingga tidak terjadinya kegagalan campuran antara agregat kasar dan agregat halus.

b. Dari hasil penelitian ini didapatkan bahwa tempurung kelapa dapat mengurangi kuat tekan beton, oleh sebab itu tempurung kelapa baik digunakan untuk jenis beton ringan.

c. Bila tempurung kelapa sebagai penambah pada campuran beton ringan sebaiknya digiling seperti agregat halus, dimana tempurung kelapa merupakan agregat dengan butiran kasar dan ringan serta mengandung aroma yang khas dan dapat sebagai beton ringan yang baik.

d. Sebelum tempurung kelapa digunakan menjadi bahan tambahan sebaiknya dilakukan pengeringan (oven) agar kadar zat dalam tempurung berkurang dan memperoleh hasil yang baik.

e. Pada percobaan selanjutnya sebaiknya dilakukan test tarik terhadap beton dengan agregat tambahan seperti tempurung kelapa ataupun sabut kelapa.

\section{Daftar Pustaka}

Anonim, 2002, SK SNI 03-2874-2002, Tata Cara Perhitungan Struktur Beton Untuk Banguan Gedung (Beta Version), Jakarta.

Gurki J. Thambah sembiring, 2010, Beton Bertulang Edisi Revisi, Rekayasa Sains, Bandung.

Mulyono Tri,Teknologi Beton, Yogyakarta, Andi, 2005.

Anonim, 1971, N.I.-2, Peraturan Beton Bertulang, Direktorat Jendral Cipta Karya Departemen Pekerjaan Umum dan Tenaga Listrik, Jakarta.

http:/ / repository.usu.ac.id/bitstream/1234567 89/28559/4/Chapter\%20II.pdf

http:/ / www.sharemyeyes.com/2013/10/temp urung-kelapa.html\#ixzz3UGt7KEK5

www.arangbatok.org/2014/karakteristikbatok-kelapa.htm 